\title{
Opportunities to engage health system leaders in whole systems approaches to physical activity in England
}

\author{
E. L. Bird ${ }^{1 *} \mathbb{D}$, D. Evans ${ }^{1}$, S. Gray ${ }^{1}$, E. Atherton², J. Blackshaw², M. Brannan², N. Corrigan ${ }^{3}$ and D. Weiner ${ }^{2}$
}

\begin{abstract}
Background: Physical activity plays an important role in maintaining good health and wellbeing, non-communicable disease prevention and can improve healthcare outcomes. Some progress is being made on incorporating physical activity into routine care, but less on engaging health system leaders in the 'whole systems' approaches which are increasingly recognised as important for addressing complex public health challenges such as physical inactivity. This commentary builds upon the findings of a recent study and aims to identify opportunities for engaging National Health Service (NHS) systems leaders in whole systems approaches to physical activity.

Opportunities for action in England: Pockets of good practice exist from which lessons can be learned, but there are systemic issues that discourage and create barriers, and a need for meaningful engagement, leadership and action at national, regional and local levels. National and regional actors like Sport England, NHS England, health professional bodies, Active Partnerships, the Local Government Association and the Office for Health Improvement and Disparities can encourage and support government and the NHS to change policy drivers, culture and practices. Emerging opportunities include the 2021 White Paper Integration and Innovation, development of local integrated care systems, leadership from health charities and investment in non-clinical interventions ('social prescribing'). At local level, public health and physical activity specialists and other organisations have a key role as champions and facilitators of local whole systems approaches and engagement of local NHS leaderships. Finally, although whole systems action is about collaborative leadership, individual champions of physical activity can make a difference in influencing NHS leaders at every level towards whole systems working.
\end{abstract}

Keywords: Whole systems approaches, Physical activity, Systems leadership, Public health, Healthcare public health

\section{Background}

Persistently high levels of physical inactivity constitute a public health problem globally [1]. Physical inactivity contributes to chronic diseases which are a burden to health care systems such as the National Health Service (NHS) in England [2, 3]. There remain stark inequalities when it comes to how physically active people are

\footnotetext{
*Correspondence: emma.bird@uwe.ac.uk

${ }^{1}$ Centre for Public Health and Wellbeing, University of the West

of England, Frenchay Campus, Bristol BS16 1QY, UK

Full list of author information is available at the end of the article
}

and the following groups are particularly affected - older people, people living in more deprived areas, people living with long term conditions and/or physical or learning disabilities and, people in Black, Asian and Minority Ethnic groups [4]. More positively, increasing physical activity has been shown to improve health and wellbeing at every age and in diverse populations $[5,6]$.

Growing recognition of the issue of physical inactivity has resulted in the publication of numerous policy drivers and strategies advocating for physical activity, including the World Health Organization's Global Action Plan on Physical Activity 2018-2030 - More Active People

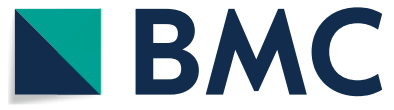

(c) The Author(s) 2022. Open Access This article is licensed under a Creative Commons Attribution 4.0 International License, which permits use, sharing, adaptation, distribution and reproduction in any medium or format, as long as you give appropriate credit to the original author(s) and the source, provide a link to the Creative Commons licence, and indicate if changes were made. The images or other third party material in this article are included in the article's Creative Commons licence, unless indicated otherwise in a credit line to the material. If material is not included in the article's Creative Commons licence and your intended use is not permitted by statutory regulation or exceeds the permitted use, you will need to obtain permission directly from the copyright holder. To view a copy of this licence, visit http://creativecommons.org/licenses/by/4.0/ The Creative Commons Public Domain Dedication waiver (http://creativeco mmons.org/publicdomain/zero/1.0/) applies to the data made available in this article, unless otherwise stated in a credit line to the data. 
for a Healthier World [7]. Investment in policies that promote physical activity can contribute positively to achieving many of the 2030 United Nations Sustainable Development Goals [7, 8]. In 2013, the World Health Organization pledged to reduce global physical inactivity prevalence by $10 \%$ by 2025 [9]. However, findings from a pooled analysis of population based survey data suggest that if current trends continue the target will not be met [10].

The COVID-19 pandemic and the necessary measures to suppress the virus has resulted in further reductions in population physical activity levels, particularly for communities with the highest health needs $[11,12]$. It has led to calls for an update to the Global Action Plan on Physical Activity (GAPPA) to reflect the 'new' state of physical activity [13]. Arguably, COVID-19 has made physical activity promotion even more urgent and provides significant opportunities for renewed action in this area.

Tackling low levels of physical activity has been an identified priority of successive UK governments (responsible for health policy in England), resulting in the publication of numerous documents, including as a legacy commitment of the London 2012 Games, $[14,15]$ and the UK government's Advancing Our Health: prevention in the 2020s Paper [16]. Some progress has been made in tackling low levels of physical activity, though it has been slow and inequalities remain for people with health issues and other groups [17]. Notably, a recent critical review of national physical activity policies in England identified 54 policy documents in circulation relating to children and young people alone [18]. This suggests that there remains a need to better connect and align policies and strategies and how best to coherently disseminate and communicate key messages to various audiences. In 2021 Sport England, a UK government body responsible for growing and developing grassroots sport and getting more people active across England published its timely Uniting the Movement strategy [19]. The strategy prioritises connecting physical activity with health and wellbeing as critical to get the population active, and provides a real moment to harness and align action through a long-term whole systems approach. There is also increasing political recognition of the importance of the link between physical activity and population health and wellbeing, including a call for a 'national sport, health and wellbeing plan' and creation of a new ministerial post with accountability within the Department of Health and Social Care [20].

\section{Whole systems approaches to physical activity}

There is growing interest in the public health field in whole systems approaches to population health in general, [21] and such approaches related to promoting physical activity in particular [22,23]. Rutter and colleagues in
2017 described a complex systems model of public health in which poor health and health inequalities are conceptualised "as outcomes of a multitude of interdependent elements within a connected whole. These elements affect each other in sometimes subtle ways, with changes potentially reverberating throughout the system" [24]. This was followed in 2019 by a paper calling for whole systems approaches to global and national physical activity plans [22].

The Global Action Plan on Physical Activity suggests that whole systems approaches are needed to combine upstream policy actions, which aim to improve social, cultural, economic and environmental factors that support physical activity, with downstream individuallyfocused approaches [7] It also highlights the need to scale-up policy actions and government strategies for physical activity. Whole systems approaches are arguably relevant and necessary to address low levels of physical activity, associated negative health impacts and wider outcomes in at-risk population groups including people from more disadvantaged communities. Physical inactivity intersects with a range of inequality issues associated with environments that discourage physical activity, including lack of access to green spaces, transport planning traditionally focused on car travel, lack of adequate infrastructure for walking and cycling and cultural attitudes towards physical activity [25].

In England, the Office for Health Improvement and Disparities (OHID), has responsibility for promoting physical activity and health (and has a lead role in promoting whole systems approaches to physical activity through the Everybody Active, Every Day framework [26]). Prior to its cessation, Public Health England had invested in systems thinking and in 2019 published Whole systems approach to obesity: a guide to support local approaches to promoting a healthy weight that, though focused on obesity, included the promotion of physical activity within its scope [27]. The development of the Everybody Active, Every Day framework [26] involved over 1000 national and local stakeholders to help address inactivity and increase physical activity. The framework promotes a whole systems cross-sector approach across four domains - active society; moving professionals; active environments; and, moving at scale. Shortly afterward the UK government published its strategy for sport and physical activity, Sporting Future, which for the first time identified improvement of health and achievement of the UK Chief Medical Officer's guidelines on physical activity as specific ambitions [28].

In recent years, at a national level in England there has been a growing collaboration across sectors led by OHID and Sport England, which has tested opportunities to enable the NHS and healthcare professionals to 
do more to promote physical activity as part of routine care [29]. For example, Sport England have recently been working on local delivery pilots (LDPs), where 12 LDPs across England have developed and piloted whole system approaches to physical activity in local communities [30]. At a more regional level, it is pertinent to note the work in Sheffield and the Move More Sheffield whole systems approach which has helped inform 'what works' to promote physical activity through the co-location of healthcare and leisure settings [31,32].

There exist many different perspectives on whole-systems approaches, with systems language sometimes used differently. This definition describes how whole systems approaches are understood in this paper:

'A local whole systems approach responds to complexity through an ongoing, dynamic and flexible way of working. It enables local stakeholders, including communities, to come together, share an understanding of the reality of the challenge, consider how the local system is operating and where there are the greatest opportunities for change. Stakeholders agree actions and decide as a network how to work together in an integrated way to bring about sustainable, long-term systems change.' [33]

\section{The NHS, whole systems approaches and systems leadership}

In England there is a concern for the health of the nation and the impact that an ageing and increasingly unhealthy population has on the financial sustainability of the NHS and wider public sector [34]. A recent LSE-Lancet Commission on the future of the NHS highlighted the unsustainability of the service and the critical need to focus on improving the population's health through prevention and health promotion [35]. This echoes the previous NHS Long Term Plan, [36] which called for a step change in action on prevention and a shift of resources from acute care to prevention. There remain challenges when it comes to public health funding and so whilst the latest public health budgets for 2021-22 in England represent a numeric increase, [37] budgets remain substantially lower than in 2015 [38-40].

Historically service delivery metrics such as performance, quality and finances have been prioritised as key performance indicators rather than prevention of ill-health and promotion of health and wellbeing [41]. Research indicates that supply of healthcare and, presumably to some degree, the actions of NHS system leaders are driven by responding to government decision and policy choices and, perhaps to a lesser degree, population health goals [42]. Moreover, there is little evidence of substantial central pressure for their involvement in long-term prevention initiatives [43]. Evaluations suggest that leadership development programmes undertaken by NHS managers and clinicians tend to focus on systems leadership and address change management in service delivery, quality or training rather than in embracing new approaches to integrating prevention into NHS services [44]. To have a significant impact on population health, NHS leaders will need to embrace a concept of systems leadership that goes beyond the health care system and acknowledge the importance of the wider and more complex social determinants of health and thus the need to work with multiple stakeholders (e.g. local authorities, education providers, criminal justice system, private sector) across their local systems [45].

"Promoting health through the organised efforts of society" is fundamental to the role of public health [46]. The shift of the local public health function from the NHS back to local authorities in England in 2013 is generally agreed to be good in principle, as local authorities are well placed to address the wider social determinants of health. However, it has proved a barrier to the NHS embracing prevention as the NHS lost the direct employment of most of its public health experts. It has also naturally created a challenge for engaging the NHS in public health objectives, for which there is opportunity to address this. The lack of a public health perspective in the NHS has been recognised and there now exists Regional Directors of Public Health [47].

\section{The advent of integrated care systems}

The NHS Long Term Plan [36] strongly expressed the policy intention to shift the focus of local NHS organisations to population health management through the establishment of integrated care systems (ICSs) covering the whole of England [48]. ICSs are intended to integrate across primary and specialist care, physical and mental health, and health and social care. In the absence of an agreed national model of the ICS, Fig. 1 presents a model of the integrated care system in Bolton, England [49]. In addition, there is a strong emphasis on prevention, although much of the focus is on secondary prevention for conditions including diabetes, obesity and respiratory illness. There is some attention given to the need for upstream interventions such as tackling air pollution, but little indication of a whole systems approach to primary prevention and no mention of the need to promote physical activity.

Similarly, the White Paper Integration and Innovation [50] states a clear commitment to integration of prevention and health and care services. However, as above, the prevention agenda is more focused on secondary rather than primary prevention. In particular, action on obesity is given a high profile, but there is no reference 


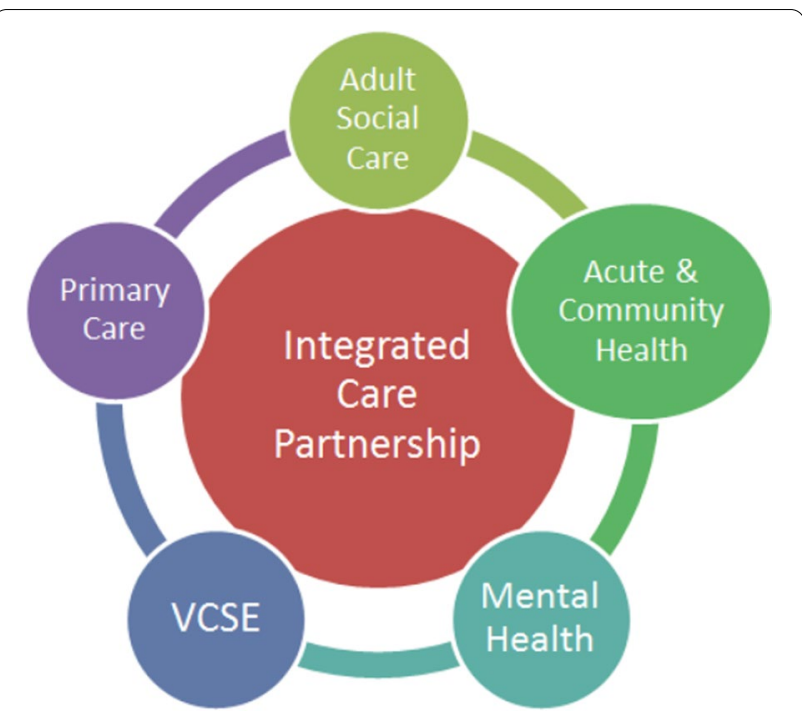

Fig. 1 The Integrated Care System - A Model [Source: 49]

to physical activity nor is the action proposed on obesity reflective of a whole systems approach. By contrast, the Advancing Our Health: prevention in the 2020s Paper [16] emphasises the potential for ICSs to contribute to both primary and secondary prevention.

It is clear that ICSs are intended to take a whole systems approach to prevention and the integration of health and care services [51]. This is reaffirmed in the government's policy paper Transforming the public health system: reforming the public health system for the challenges of our times, [52] which encouragingly signals the intention to strengthen the NHS role in prevention of ill-health, and articulates the requirement for ICSs to partner with non-NHS bodies when it comes to population health and meeting local needs. This policy paper also helps to set out the future for health improvement and public health and, at a national level, sets the scene for the recent establishment of the Office for Health Improvement and Disparities.

\section{The project to engage NHS systems leaders in whole systems approaches to physical activity}

Despite health care being one of the top eight best investments for increasing physical activity, [53] there are few published studies that examine how to involve health system leaders in whole systems approaches, [54] and none we identified which address how to involve the NHS in promoting physical activity in particular. To help address this lack of evidence, Public Health England commissioned the University of the West of England, Bristol (UWE Bristol) to carry out qualitative research exploring experiences of engaging NHS leaders in whole systems approaches to physical activity. This project has been reported elsewhere, [54] but briefly, eight interviews were conducted with national stakeholders working across England in different parts of the system, including for example, those from NHS England and NHS Improvement (NHSE\&I) and the Local Government Association. The aim of these interviews was to gain a high-level overview of NHS engagement in whole systems activity. National interviews were complemented by interviews with 22 local informants from four case study sites in England that were identified as implementing whole systems approaches to physical activity. Two case study sites were Local Delivery Pilots (LDPs) and two were not. The four local practice examples presented diverse contexts and approaches to engaging NHS leaders in whole systems approaches to physical activity, but all had done so to different degrees. Local informants from each case study site were purposively sampled to represent different levels of the local system. Data were thematically analysed [55] and ten key themes identified (Additional File 1). The study was granted ethical approval by the University of the West of England Research Ethics Committee (Ref: HAS.20.01.095).

\section{Main text}

\section{Opportunities for action in England}

In our original study [54] we identified a number of common enablers and common barriers to engaging NHS systems leaders in whole systems approaches to physical activity. These are summarised in Table 1 . For the purposes of this commentary, we build upon the barriers and enablers presented in Table 1 and identify opportunities for action to engage health system leaders in whole systems approaches to physical activity in England, at least in the short to medium term.

The advent of ICSs in England presents an opportunity to begin to address three barriers identified in our research, namely: Capacity of the NHS and other sectors; NHS culture; and, Engaging the acute sector (Table 1). Whilst there is positive local practice relating to physical activity and systems approaches, to build upon as demonstrated through for example the LDPs, there remains ample opportunity to spread this learning more broadly to NHS systems and their leaders. Engaging NHS leaders will require collaborative approaches at national, regional and local levels, including between organisations such OHID and Sport England. Consideration is also required as to how to place more emphasis on promoting physical activity to support population health. A recent scoping review noted the importance of how physical activity messages are communicated, finding consistent support for the role of positive framing of physical activity 
Table 1 Common enablers and barriers to engaging NHS leaders in whole systems approaches to physical activity (Adapted from: Evans et al., 2020) [52]

\section{Enablers}

Recognising and facilitating shared system leadership

Key individuals or core teams championing the whole systems approach

Key facilitation role for public health across the system

Balancing senior buy-in with working with enthusiasts

Taking time to build relationships and develop a shared vision

\section{Barriers}

Capacity - for the NHS and other sectors

NHS culture

Engaging the acute sector

Difficulty in demonstrating quantifiable impact in the short to medium term

Difficulty in seeing opportunities for innovation that do not involve significant new resources

\section{Description}

An explicit commitment to both a whole systems approach to physical and to facilitating shared systems leadership.

Although overall leadership needs to be shared, motivated individuals or small core teams working across local authorities and the NHS (particularly in CCGs) can make a difference in championing a whole systems approach to physical activity.

All actors bring different knowledge and skills to the table, but public health professionals uniquely have the evidence-based knowledge about effective physical activity interventions, the understanding of systems approaches, the partnership skills and the remit to play a key facilitation role in promoting physical activity across sectors including in the NHS.

Gaining 'buy-in'from senior managers in the NHS is important (particularly to secure any necessary financial support) but it is recognised that senior managers often or usually have little time to personally engage, and once they have given broad approval for physical activity work, they might have relatively little engagement with or knowledge of the detail. Achieving real change often a result of working opportunistically with enthusiasts, whatever their formal status or level of authority whilst securing in principle support and buy-in from those in more senior leadership positions.

The importance of relationship building (including the time it takes build trust in relationships) and developing shared vision and shared values.

\section{Description}

Members of the NHS system - and other sectors - have many competing priorities, and their capacity to engage with the physical activity agenda is often experienced as limited.

NHS performance management is traditionally focused on clinical treatment and care, quality and finance, and despite the stated commitment to prevention does not currently encourage a focus on the long-term benefits of promoting physical activity

Promoting physical activity is still something that is not usually seen as acute sector'core' business.

The main benefits of greater physical activity are likely to accrue over a long-time period - 5 to 10 years or more - whilst the NHS is looking for short term reductions in indicators like bed days.

A lack of resources is not necessarily a barrier to innovation around physical activity, but there is a perception that stakeholders in the NHS and other parts of the system perceive this as an important barrier.

CCG Clinical Commissioning Group, GP General Practice, NHS National Health Service

messages, highlighting the short-term outcomes of physical activity, and tailoring/targeting of message content [56].

Recognition of the need to address inequalities in physical activity for people with health conditions, and support them to be active for good health and wellbeing, and to help manage their conditions has increased across health and physical activity sectors. The Richmond Group of Charities working across health and social care has established a 'Movement for all' programme and the 'We Are Undefeatable' campaign to promote physical activity to people with long term conditions. A recent consensus statement on physical activity risk endorsed by these charities recommended that the benefits outweigh the risks for most people with health conditions to get active [57]. Sport England has also identified people with long-term conditions as a priority group in their latest action plan [58]. Investment in social prescribing services - signposting people to non-clinical community based interventions - provides an opportunity, with regional Physical Activity Advisors appointed to support and coordinate [59].

Placing stronger emphasis on how physical activity is promoted could help to engage NHS systems leaders with specific physical activity initiatives and wider systemic prevention partnerships; once NHS systems leaders sign up to such engagement, their directors and other senior staff are likely to follow. It may also provide an opportunity for innovation that does not involve significant new resources - a barrier identified in our research 
(Table 1). Possible strategies could involve information sharing at key NHS webinars, events and conferences and in NHS policies and guidance, and/or the development and dissemination of tailored easily accessible resources on physical activity that would support conversations with different audiences within the NHS.

There is a need to be flexible in accordance with the structures, priorities and roles of systems at national, regional and local levels. As previously highlighted in the Global Activity Plan on Physical Activity [7] our research also identified that partnerships are key and are likely to be influenced and supported by a range of stakeholders and organisations, therefore whilst one or multiple organisations may take a lead there will be a need for shared ownership and action across organisations and level. If such collaboration can be achieved it could build upon two key enablers identified in our research (Table 1): Recognising and facilitating shared system leadership and Taking time to build relationships and develop a shared vision.

National actors (for example, Sport England, NHS England, health professional bodies, Active Partnership Network, the Local Government Association and OHID) need to collaborate, harness the evidence and practice on the benefits of systems approaches to support and influence change at the national policy level. Recent research, however, has suggested that the good intentions expressed in policy are not always carried through into implementation and they tend to have an individualistic rather than a whole systems perspective $[60,61]$; the opposite approach to those expressed in key policy drivers and strategies advocating for physical activity [7, 8]. Regional and local actors like ICSs, local authorities and Active Partnerships are therefore a pivotal part of a broad-brush alliance to influence government policy towards a more systems approach to physical activity in the NHS. A critical point for consideration is how to continue co-working with the recently established OHID and take forward its commitment to support whole systems working across all its prevention agendas, including physical activity. It is vital that efforts are continued at a national and local level, when it comes to exploring and enabling delivery on whole systems working on physical activity.

The most recent White Paper [50] and the changes that will follow presents another fruitful opportunity to begin to address the barriers discussed above (Table 1: Capacity of the NHS and other sectors; NHS culture; and, Engaging the acute sector). Whenever there is major system change, as there will be following the White Paper, there is an opportunity to influence the direction of change. Moreover, given the impact of COVID-19 on the NHS system, the learning gleaned from systems approaches and the recovery to follow, again creates opportunities as the system realigns to engage prevention as part of the solution. The White Paper explicitly calls for greater innovation, flexibility, collaborative working and population health focus - all elements conducive to a whole systems approach to physical activity. The challenge will be in giving the whole systems approach a strong voice amongst all the other competing demands and priorities ICSs will be grappling with. Physical activity stakeholders will need to engage at all levels of the system - OHID and the newly merged NHS England (for example, embedding strong whole systems approaches to prevention in guidance to ICSs) will need to influence the ICSs directly.

A key strategic action to consider is how to rebuild and enhance public health integration in and with the NHS so that there are increasing opportunities to support Key individuals or core team championing of whole systems approaches for physical activity (Table 1). Our research highlighted the important impact that individual champions of physical activity can make in influencing NHS leaders at every level towards whole systems working. Systems leadership is, by definition, about collaborative and distributed leadership, but individuals can still make a difference as catalysts for action within complex systems. Scaling up and extending across England, the pockets of positive local practice, where individuals and public health teams work cohesively with the NHS, is therefore crucial for addressing the wider determinants of health and for promoting everyday physical activity. Successfully doing so will, however, mean that it is important to address barriers including Capacity of the NHS and other sectors and NHS culture (Table 1). For example, prospective champions for physical activity in the NHS, including managers and clinicians, will need to be creative; and use any spare capacity to seek collaboration with public health teams and combine their skills and experience to champion a whole systems approach. The recent ICS guidance [48] requires the ICS to integrate a public health voice at the 'place' level, which facilitates the role of the Director of Public Health. Whilst these developments will help to establish a platform to drive prevention and place it at the heart of ICS thinking, there remains opportunity to strengthen the tools to support systems thinking. Such efforts would build upon an enabler identified in our research: Key facilitation role for public health across the system (Table 1).

Our research identified the importance of Balancing senior buy-in with working with enthusiasts (Table 1). In these COVID-19 times, NHS leaders will inevitably have many competing demands, so ensuring action on physical activity becomes a priority in the NHS will require the continued championing of whole systems approaches by stakeholder organisations (including Sport England, the 
Faculty of Public Health, the Local Government Association and national government bodies) and other enthusiasts. NHS leaders can be supported in this work by the reality that physical activity is high up the current political agenda with a focus on active transport and the need to address current levels of obesity. A key argument will be to use evidence on the unintended negative impact of COVID-19 on physical activity levels as a catalyst for change to embed and align whole systems approaches to physical activity within the structures of the ICS and NHS performance management processes. Taking such action would begin to address three barriers identified in our research: Difficulty in demonstrating quantifiable impact in the short to medium term; and, Engaging the acute sector; and, NHS culture.

To further build upon the enablers identified above, stakeholder organisations can support regional and local partnerships to adopt whole systems approaches to physical activity, as demonstrated through the journeys of the twelve local delivery pilots (LDPs) [30]. Within the NHS, ICSs are the obvious vehicle to embed a whole systems approach to physical activity and there is much learning from the LDPs and others' experiences to enable the health community to make this happen. All ICSs will have a population health management programme that should embed a whole systems approach to prevention, working closely with public health in local authorities, and recognise the important role of physical activity as a key part of a holistic and joined-up approach in commissioning plans. Where they exist, Active Partnerships (https://www.activepartnerships.org/) can also play a key role in facilitating a whole systems approach at the health community level.

At a neighbourhood level in health and wellbeing boards, NHS trusts and primary care networks, there will be a critical role for local authority public health departments. Local authority public health specialists will need to continue to provide the champions and facilitators for whole systems working on prevention in general and physical activity in particular at the ICS level. The COVID-19 pandemic and living with COVID-19 will remain the context within which the system is working for some time to come. Whilst this has undoubtedly challenged the public health and NHS workforce, there has been reference to the importance of systems approaches in the response to COVID-19 [62] and it would seem relevant for systems approaches to underpin recovery. This should provide opportunities for the NHS to further its leadership in health improvement and areas like physical activity and thus build upon enablers Key facilitation role for public health across the system and Key individuals or core teams championing the whole systems approach identified in our research (Table 1).
At every organisational level in England (national, regional, local), there is a need to build the evidence base around what works in whole systems working on physical activity. OHID and academic institutions among others have begun to develop this evidence $[4,23]$ but there is much more to do. Academic researchers can play a vital role in further evaluating whole systems approaches to physical activity and disseminating the results, in particular to demonstrate to NHS leaders the value of such approaches to the NHS. There is also the opportunity to learn from the wider literature on systems working and systems leadership in public health and synthesise this learning through systematic reviews and apply to physical activity work. Building a shared approach and understanding between academic researchers and policy makers and NHS leaders will not be without its challenges. However, different actors have what can appear to be conflicting needs; NHS leaders and policy makers operate in an often pressurised environment where they need answers immediately whilst academic research often requires years to come to robust conclusions [24]. As Rutter and colleagues make clear, there is no simple mechanism to address this challenge, but seeing it as part of the whole system approach is a start.

Changing the culture of the NHS to embrace whole systems working also has educational implications for the NHS Leadership Academy, the Medical Royal Colleges, Health Education England, universities, and others concerned with the education of NHS leaders, managers and senior clinicians. One example of good practice is a collaborative project that is already underway between the Royal College of General Practitioners and Sport England [63]. The Active Practice Charter seeks to inspire and celebrate practices that are taking steps to increase activity and reduce sedentary behaviour in their patients and staff. This offers a real opportunity to embed physical activity into care pathways in a way that could support a whole systems approach and to directly address $N H S$ culture which does not currently encourage a focus on physical activity; a key barrier identified in our research (Table 1).

\section{Conclusions}

Promoting physical activity and contributing to whole systems approaches to physical activity is crucial for health systems improving population health and managing demand, including for the NHS in England. There are pockets of good practice from which lessons can be learned, but there is a need for whole systems approaches as part of a broader, holistic, prevention agenda. Action is required at all levels, particularly in identifying and addressing underlying system barriers, to make participating in whole systems action in the 
NHS a reality. Engagement of NHS leaders with physical activity at a system level remains variable and so it is vital to consider, within national structures and at a local level, how this can be changed, and which drivers are needed. The White Paper on NHS integration and innovation, in addition to development of Integrated Care Systems and Sport England's Uniting the Movement strategy, provide a platform to address this. Furthermore, actors including Sport England, NHS England, health professional bodies, Active Partnerships, the Local Government Association and OHID, need to collaborate, harness the evidence and practice on the benefits of systems approaches to support and influence change. These organisations also need to continue to enable and support local physical activity partnerships to engage the NHS and local authorities. Finally, public health specialists have a key role as champions and facilitators of whole systems approaches to prevention in general and physical activity in particular.

\begin{abstract}
Abbreviations
GAPPA: Global Action Plan on Physical Activity; ICS: Integrated care system; LDPS: Local delivery pilot; NHS: National Health Service; OHID: Office for Health Improvement and Disparities; WHO: World Health Organization; PHE: Public Health England.
\end{abstract}

\section{Supplementary Information}

The online version contains supplementary material available at https://doi. org/10.1186/s12889-022-12602-5.

Additional file 1.

\section{Acknowledgements}

We would like to thank Charlene Simon, Jessica Lee and Ellen Lithgow for their contributions to the original study. Thanks also to the study participants, with particular thanks to those who facilitated the case studies.

\begin{abstract}
Authors' contributions
The study was conceived by DE, ELB and SG. DE and ELB led data collection and analysis. DE and ELB interpreted the data, with feedback from SG. ELB, DE and SG wrote and edited the manuscript, with feedback and revision for important intellectual content from EA, JB, MB, NC and DW. All authors provided critical edits and revisions to the paper and have reviewed and approved the final version of the paper.
\end{abstract}

\section{Authors' information}

ELB is a Senior Lecturer in Public Health in the Centre for Public Health and Wellbeing at the University of the West of England, Bristol, UK. DE is Professor in Health Services Research in the Centre for Public Health and Wellbeing at the University of the West of England, Bristol, UK. SG is Professor of Public Health in the Centre for Public Health and Wellbeing at the University of the West of England, Bristol, UK. EA is Senior Scientific Officer, Obesity and Healthy Weight, Office for Health Improvement and Disparities. JB is National lead, Physical Activity and Healthy Weight, Office for Health Improvement and Disparities. MB is Interim Consultant in Public Health, London Borough of Lewisham (seconded from Office for Health Improvement and Disparities). NC is Healthy Places \& Sustainable Communities Programme Lead, North East \& Yorkshire Region, Office for Health Improvement and Disparities. DW is Senior
Scientific Officer, Obesity and Healthy Weight, Office for Health Improvement and Disparities.

\section{Funding}

The work was supported by Public Health England (now Office for Health Improvement and Disparities). This research was conducted on the principle of co-production between the University of the West of England, Bristol (UWE Bristol) and Public Health England; there was close working and collaboration between the two partners in the planning and management of the project. PHE was particularly involved in identifying relevant national stakeholders and potential case studies. UWE Bristol approached individuals and case studies for involvement and independently conducted the data collection, analysis and interpretation of findings. Public Health England provided critical edits and revisions to the paper and reviewed and approved the final version of the paper. The views expressed in the publication are those of the authors and not necessarily those of the Office for Health Improvement and Disparities.

\section{Availability of data and materials}

This study does not have ethical approval to make the study dataset publicly available. Data may be available from the corresponding author on reasonable request.

\section{Declarations}

\section{Ethics approval and consent to participate}

An assessment of potential ethical risks was undertaken prior to submission for ethical review and the project was considered to be relatively low risk as there was no need or intention to collect sensitive personal data. The main potential risks identified concerned possible breaches of confidentiality and data protection. The protocol and associated ethical material (participant information sheet, consent form, privacy notice) were reviewed by UWE Bristol's Research Ethics Committee and approval given to proceed, reference HAS.20.01.095.

\section{Consent for publication \\ Not applicable.}

\section{Competing interests}

None declared.

\section{Author details}

${ }^{1}$ Centre for Public Health and Wellbeing, University of the West of England, Frenchay Campus, Bristol BS16 1 QY, UK. ${ }^{2}$ Office for Health Improvement and Disparities, Department of Health and Social Care, 39 Victoria Street, London SW1H 0EU, UK. ${ }^{3}$ Office for Health Improvement and Disparities, Department of Health and Social Care, Blenheim House, West One, Duncombe Street, Leeds LS1 4PL, UK.

Received: 26 August 2021 Accepted: 19 January 2022

Published online: 08 February 2022

\section{References}

1. Guthold R, Stevens GA, Riley LM, Bull FC. Worldwide trends in insufficient physical activity from 2001 To 2016: a pooled analysis of 358 populationbased surveys with 1.9 million participants. Lancet Global Health. 2018. https://doi.org/10.1016/S2214-109X(18)30357-7.

2. Ding D, Varela A, Bauman A, Ekelund U, Lee I-M, Heath G, et al. Towards better evidence-informed global action: lessons learnt from the lancet series and recent developments in physical activity and public health. $\mathrm{Br}$ J Sports Med. 2020;54:462-8.

3. Scarborough P, Foster C, Cobiac L, Cowburn G, Matthews A, Milton K, et al. Translating the World Health Organization $25 \times 25$ goals into a United Kingdom context: the PROMISE study. London: Richmond Group; 2016. https:/richmondgroupofcharities.org.uk/sites/default/files/the_promise_ study_final_report.pdf. Accessed 10 Aug 2021

4. Public Health England. Everybody active, every day: an evidence-based approach to physical activity. London: Public Health England; 2014. https://assets.publishing.service.gov.uk/government/uploads/system/ 
uploads/attachment_data/file/353384/Everybody_Active_Every_Day evidence_based_approach_CONSULTATION_VERSION.pdf. Accessed 10 Aug 2021

5. UK Chief Medical Officers. UK Chief Medical Officers' physical activity guidelines: UK Chief Medical Officers. London: Department of Health; 2019. https:/assets.publishing.service.gov.uk/government/uploads/ system/uploads/attachment_data/file/832868/uk-chief-medical-officersphysical-activity-guidelines.pdf. Accessed 10 Aug 2021.

6. Bull FC, Al-Ansari SS, Biddle S, Borodulin K, Bauman MP, Cardon G, et al. World Health Organization 2020 guidelines on physical activity and sedentary behaviour. BJSM. 2020;54:1451-62.

7. World Health Organization. Global action plan on physical activity 2018-2030. More active people for a healthier world: World Health Organization, Geneva; 2017.

8. Salvo D, Garcia L, Reis RS, Stankov I, Goel R, Schipperijn J, et al. Physical activity promotion and the United Nations sustainable development goals: building synergies to maximise impact. J Phys Act Health. 2021. https://doi.org/10.1123/jpah.2021-0413.

9. World Health Organization. Global action plan for the prevention and control of non-communicable diseases, 2012-2020. Geneva: World Health Organization; 2013. https://www.who.int/nmh/events/ncd_action_plan/ en/. Accessed 23 Nov 2021.

10. Guthold R, Stevens GA, Riley LM, Bull FC. Worldwide trends in insufficient physical activity from 2001 to 2016: a pooled analysis of 358 populationbased surveys with 1.9 million participants. The lancet Glob Health. 2018;6(10):E1077-86.

11. Tison G, Avram R, Kuhar P, Abreau S, Marcus G, Pletcher M, et al. Worldwide effect of COVID-19 on physical activity: a descriptive study. Ann Intern Med. 2020. https://doi.org/10.7326/M20-2665.

12. Sport England. Active lives adult survey mid-march to mid-may 2020: coronavirus (COVID-19) report. London: Sport England; 2020. https:// sportengland-production-files.s3.eu-west-2.amazonaws.com/s3fs-public/ 2020-10/Active\%20Lives\%20Adult\%20May\%2019-20\%20Coronavirus\% 20Report.pdf?2L6TBVV5UvCGXb_VxZcWHcfFXO_wRal7. Accessed 10 Aug 2021.

13. Amini H, Habibi S, Islamoglu AH, Isanejad E, Uz C, Daniyari H. COVID-19 pandemic-indced physical inactivity and the necessity of updating the global action plan on physical activity 2018-2030. Environ Health Prev Med. 2021. https://doi.org/10.1186/s12199-021-00955-z.

14. Department of Culture, media and sport. Before, during and after: making the most of the London 2012 games. London: Department of Culture, Media and Sport; 2008. http://data.parliament.uk/DepositedPapers/Files/ DEP2008-1453/DEP2008-1453.pdf. Accessed 10 Aug 2021.

15. Her Majesty's Government. Moving more, living more: the physical activity olympic and paralympic legacy for the nation: Her Majesty's Government; 2014. https://www.gov.uk/government/publications/moving-more-living-more-olympic-and-paralympic-games-legacy. Accessed 10 Aug 2021

16. Cabinet Office. Department of health and social care. Advancing our health: prevention in the 2020s. London: Cabinet office, Department of Health and Social Care; 2019. https://assets.publishing.service.gov.uk/ government/uploads/system/uploads/attachment_data/file/819766/ advancing-our-health-prevention-in-the-2020s-accessible.pdf. Accessed 10 Aug 2021

17. Sport England. Active lives adult survey. May 2019/20. London: Sport England; 2020. https://sportengland-production-files.s3.eu-west-2.amazo naws.com/s3fs-public/2020-10/Active\%20Lives\%20Adult\%20May\%201920\%20Report.pdf?Versionld=AYzBswpBmlh9cNcH8TFctPI38v4Ok2JD. Accessed 10 Aug 2021.

18. Chalkley A, Milton K. A critical review of national physical activity policies relating to children and young people in England. J Sport Health Sci. 2021;10(3):255-62.

19. Sport England. Uniting the movement: our 10-year vision to transform lives and communities through sport and physical activity. London: Sport England; 2021. https://www.sportengland.org/why-were-here/unitingthe-movement. Accessed 10 Aug 2021.

20. UK Parliament. A new national plan for sport, health and wellbeing is needed to tackle inactivity says lords committee. London: UK Parliament; 2021. https://committees.parliament.uk/committee/482/natio nal-plan-for-sport-and-recreation-committee/news/159591/a-new-natio nal-plan-for-sport-health-and-wellbeing-is-needed-to-tackle-inactivitysays-lords. Accessed 16 Dec 2021.

21. Stansfield J, South J, Mapplethorpe T. What are the elements of a whole system approach to community-centred public health? A qualitative study with public health leaders in England's local authority areas. BMJ Open. 2020. https://doi.org/10.1136/bmjopen-2019-036044.

22. Rutter H, Cavill N, Bauman A, Bull F. Systems approaches to global and national physical activity plans. Bull World Health Organ. 2019. https:// doi.org/10.2471/BLT.18.220533.

23. Bagnall A-M, Radley D, Jones R, Gately P, Nobles J, Van Dijk M, et al. Whole systems approaches to obesity and other complex public health challenges: a systematic review. BMC Public Health. 2019. https://doi.org/10. 1186/s12889-018-6274-z.

24. Rutter H, Savona N, Glonti K, Bibby J, Cummins S, Finegood DT, et al. The need for a complex systems model of evidence for public health. Lancet. 2017. https://doi.org/10.1016/S0140-6736(17)31267-9.

25. Bird EL, Ige JO, Pilkington P, Pinto A, Petrokofky C, Burgess-Allen J. Built and natural environmental planning principles for promoting health: an umbrella review. BMC Public Health. 2018;18(930).

26. Public Health England. Everybody active, every day: two years on. An update on the national physical activity framework. London: Public Health England; 2017. https://assets.publishing.service.gov.uk/gover nment/uploads/system/uploads/attachment_data/file/601298/Every body_active_every_day_2_years_on.pdf. Accessed 10 Aug 2021

27. Public Health England. Whole systems approach to obesity: a guide to support approaches to promoting a health weight. London: Public Health England; 2019. https://assets.publishing.service.gov.uk/gover nment/uploads/system/uploads/attachment_data/file/820783/Whole_ systems_approach_to_obesity_guide.pdf. Accessed 10 Aug 2021

28. Department of Culture Media and Sport. Sporting future: a new strategy for an active nation. London: Department of Culture Media and Sport; 2015. https://assets.publishing.service.gov.uk/government/uploads/ system/uploads/attachment_data/file/486622/Sporting_Future_ACCES SIBLE.pdf. Accessed 10 Aug 2021.

29. Milton K, Cavil N, Bauman A. Intersectoral partnership: a potential legacy success of the London 2012 olympic and paralympic games. Int I Sport Policy Polit. 2018. https://doi.org/10.1080/19406940.2018.1522659.

30. Sport England. People and places: the story of doing things differently. London: Sport England; 2021. https://www.sportengland.org/campa igns-and-our-work/local-delivery\#thestoryofdoingitdifferently-12539. Accessed 10 Aug 2021.

31. Tew GA, Copeland RJ, Till SH. Sport and exercise medicine and the olympic health legacy. BMC Med. 2012;10:74.

32. Grinvalds N, Shearn K, Copeland RJ, Speake H. What works to facilitate the promotion of physical activity in co-located healthcare and leisure settings: a realist review. SportRxiv. 2019. https://doi.org/10.31236/osf.io/ h9r8w.

33. Public Health England. Whole systems approach to obesity: a guide to support approaches to promoting a health weight. London: Public Health England; 2019. https://assets.publishing.service.gov.uk/gover nment/uploads/system/uploads/attachment_data/file/820783/Whole_ systems_approach_to_obesity_guide.pdf. Accessed 10 Aug 2021

34. Selbie D. Prevention and the NHS long term plan: 3 ways we can save more lives. London: Public Health England; 2018. https://publichealthmat ters.blog.gov.uk/2018/09/06/prevention-and-the-nhs-long-term-plan-3ways-we-can-save-more-lives/. Accessed 10 Aug 2021.

35. Anderson M, Pitchforth E, Asaria M, Brayne C, Casadei B, Charlesworth A, et al. LSE-lancet commission on the future of the NHS: re-laying the foundations for an equitable and efficient health and care service after COVID-19. Lancet. 2021. https://doi.org/10.1016/S0140-6736(21)00232-4.

36. NHS England. The NHS long term plan. London: NHS England; 2019. https://www.longtermplan.nhs.uk/publication/nhs-long-term-plan/. Accessed 10 Aug 2021

37. Department of Health and Social Care. Public health grants to local authorities: 2021 to 2022. London: Department of Health and Social Care; 2021. https://www.gov.uk/government/publications/public-healthgrants-to-local-authorities-2021-to-2022. Accessed 10 Aug 2021.

38. Evans D. What price public health? funding the local public health system in England post-2013. Crit Public Health. 2020. https://doi.org/10.1080/ 09581596.2020.1713302. 
39. The King's fund. Public health: our position. London: The King's Fund; 2020. https://www.kingsfund.org.uk/projects/positions/public-health. Accessed 10 Aug 2021.

40. Finch D, Bibby J, Elwell-Sutton T. Taking our health for granted: plugging the public health grant funding gap. Londoen: The Health Foundation; 2018. https://www.health.org.uk/publications/taking-our-health-forgranted. Accessed 10 Aug 2021

41. NHS Improvement. Monitor 2019/20 Annual Report. https://www.engla nd.nhs.uk/wp-content/uploads/2021/01/nhs-monitor-annual-report2019-20.pdf. Accessed 10 Aug 2021.

42. Tallack C, Charlesworth A, Kelly E, McConkey R, Rocks S. The bigger picture: learning from two decades of changing NHS care in England. London: The Health Foundation; 2020. https://www.health.org.uk/publi cations/reports/the-bigger-picture. Accessed 10 Aug 2021.

43. Jones L, Exworthy M, Frosini F. Implementing market-based reforms in the English NHS: bureaucratic coping strategies and social embeddedness. Health Policy. 2013;111(1):52-9.

44. Malby B, Merwyn K, Meredith G. Darzi alumni network. Longitudinal study of the impact of the London Darzi fellowship programmes: years 1-8. London: London South Bank University; 2017. https://www.lsbu.ac. uk/_data/assets/pdf_file/0007/122758/longitudinal-study-darzi-fello wship.pdf. Accessed 10 Aug 2021

45. Bigland C, Evans D, Bolden R, Rae M. Systems leadership in practice: thematic insights from three public health case studies. BMC Public Health. 2020:20:1735

46. Acheson D. Independent inquiry into inequalities in health. London: Her Majesty's Stationery Office; 1998. https://assets.publishing.service.gov.uk/ government/uploads/system/uploads/attachment_data/file/265503/ih. pdf. Accessed 10 Aug 2021.

47. Selbie D. Duncan Selbie's Friday message - 18 January 2019. London: Public Health England; 2019. https://publichealthmatters.blog.gov.uk/ 2019/01/18/duncan-selbies-friday-message-18-january-2019/. Accessed 10 Aug 2021.

48. NHS. Integrated care systems: guidance. London: NHS; 2021. https:// www.england.nhs.uk/publication/integrated-care-systems-guidance/. Accessed 23 Nov 2021.

49. Bolton Health and Care Partnership. 2021. https://www.boltonhcp.org.uk/ Accessed 16 Dec 2021.

50. Department of Health and Social Care. Integration and innovation: Working together to improve health and social care for all. London: Department of Health and Social Care; 2021. https://www.gov.uk/government/ publications/working-together-to-improve-health-and-social-care-for-all. Accessed 10 Aug 2021

51. The Association of Directors of Public Health (UK). Responding to the launch of the Office for Health Promotion. 2021. https://www.adph. org.uk/2021/03/statement-responding-to-the-launch-of-the-office-forhealth-promotion/. Accessed 10 Aug 2021.

52. Department of Health and Social Care. Transforming the public health system: reforming the public health system for the challenges of our times. London: Department of Health and Social Care; 2021. https:// www.gov.uk/government/publications/transforming-the-public-healthsystem/transforming-the-public-health-system-reforming-the-publichealth-system-for-the-challenges-of-our-times. Accessed 10 Aug 2021.

53. Milton K, Cavill N, Chalkley A, Foster C, Gomersall S, Hagstromer M, Kelly P, Kolbe-Alexander T, Mair J, McLaughlin M, Nobles J, Reece L, Shilton T, Smith BJ, Schipperijn J. Eight Investments That Work for Physical Activity. J Phys Activ Health. 2021;18(6).

54. Evans D, Bird EL, Gray S, Atherton E, Lee J, Simon C, et al. Engaging NHS system leaders in whole systems approaches to physical activity. London: Public Health England; 2020. https://assets.publishing.service.gov.uk/ government/uploads/system/uploads/attachment_data/file/941414/ WSA_and_NHS_report_27.11.20_2_.pdf. Accessed 10 Aug 2021

55. Braun V, Clarke V. Using thematic analysis in psychology. Qual Res Psychol. 2006:3:77-101.

56. Williamson C, Baker G, Mutrie N, Niven A, Kelly P. Get the message? A scoping review of physical activity messaging. IJBNPA. 2020;17(51).

57. Reid H, Ridout AJ, Tomaz SA, Kelly P, Jones N. On behalf of the physical activity risk consensus group. Benefits outweigh the risks: a consensus statement on the risks of physical activity for people living with long-term conditions. BJSM. 2021. https://doi.org/10.1136/bjspo rts-2021-104281.
58. Sport England. Implementation plan: years 2-4 (2022-25). London: Sport England; 2021. https://www.sportengland.org/why-were-here/unitingmovement/implementation-plan-years-2-4-2022-25. Accessed 16 Dec 2021.

59. Sport England. Why social prescribing is needed more than ever. London: Sport England; 2021. https://www.sportengland.org/blogs/why-socialprescribing-needed-more-ever. Accessed 16 Dec 2021.

60. Theis D, White M. Is obesity policy in England fit for purpose? Analysis of government strategies and policies, 1992-2020. Milbank Q. 2021. https:// doi.org/10.1111/1468-0009.12498.

61. Cheater S. Obesity crisis: comprehensive, committed and robust action needed. Int J Health Promot Educ. 2020;58(6):359-60.

62. HM Government. Build Back better: plan for growth. London: HM Government; 2021. https://www.gov.uk/government/publications/build-backbetter-our-plan-for-growth. Accessed 23 Nov 2021.

63. Royal College of General Practitioners. GP practices supported to recommend active lifestyles to patients and staff with launch of new UK-wide active practice charter. London: Royal College of General Practitioners; 2019. https://www.rcgp.org.uk/about-us/news/2019/august/gp-pract ices-supported-to-recommend-active-lifestyles-to-patients-and-staff.aspx Accessed 23 Nov 2021

\section{Publisher's Note}

Springer Nature remains neutral with regard to jurisdictional claims in published maps and institutional affiliations.

Ready to submit your research? Choose BMC and benefit from:

- fast, convenient online submission

- thorough peer review by experienced researchers in your field

- rapid publication on acceptance

- support for research data, including large and complex data types

- gold Open Access which fosters wider collaboration and increased citations

- maximum visibility for your research: over 100M website views per year

At BMC, research is always in progress.

Learn more biomedcentral.com/submissions 